\title{
CFD simulation of pressure fluctuation characteristics in the gas-solid fluidized bed: Comparisons with experiments
}

\author{
Wang Qingcheng ${ }^{1,2}$, Zhang Kai ${ }^{2,3 *}$ and Gu Hongyan ${ }^{4}$ \\ ${ }^{1}$ Beijing Shenwu Thermal Energy Technology Co., LTD, Beijing 102200, China \\ ${ }^{2}$ State Key Laboratory of Heavy Oil Processing, China University of Petroleum, Beijing 102249, China \\ ${ }^{3}$ National Engineering Lab for Biomass Power Generation Equipment, North China Electric Power University, Beijing \\ 102206, China \\ ${ }^{4}$ Electrical Engineering College, Guizhou University, Guiyang 550025, China
}

(C) China University of Petroleum (Beijing) and Springer-Verlag Berlin Heidelberg 2011

\begin{abstract}
A simple hydrodynamic model based on two-fluid theory, taking into account the effect of discrete particles on both the gas- and solid-phase momentum equations, was used to numerically investigate the pressure fluctuation characteristics in a gas-solid fluidized bed with the aid of CFX 4.4, a commercial CFD software package, by adding user-defined Fortran subroutines. Numerical simulations together with typical experimental measurements show that pressure fluctuations originate above the distributor when a gas pulse is injected into the fluidized bed. The pressure above the bubble gradually increases due to the presence of a rising bubble. When the bubble passes through the bed surface, the pressure near the bed surface gradually decreases to a lower value. Moreover, the pressure signals in the bubbling fluidized beds show obviously periodic characteristics. The major frequency of pressure fluctuations at the same vertical position is affected slightly by the operating gas velocity, and the amplitude of pressure fluctuations is related to both the operating gas velocity and the vertical height. In this study, the influence of the operating gas velocity on the pressure wave propagation velocity can be ignored, and only two peak frequencies in the power spectrum of the pressure fluctuations are observed which are associated with the bubble formation above the distributor and its eruption at the bed surface.
\end{abstract}

Key words: Gas-solid fluidized bed, CFD simulation, experimental measurements, propagation of pressure fluctuations, pressure wave velocity, pressure fluctuation frequency

\section{Introduction}

Fluid catalytic cracking (FCC) units have been used to convert heavy oil or residue to gasoline, heating oil and diesel fuel. This is becoming more important with decreasing oil production and rapidly rising prices of conventional oils (Kim et al, 2000). FCC catalyst regenerators are generally operated as a dense fluidized bed. It is well known that pressure fluctuation is a significant indicator for predicting the dynamic behavior of fluidized beds. Therefore, the pressure fluctuations in the regenerator play an important role in optimizing the operating conditions of FCC units.

In the past 40 years, many investigations into the pressure characteristics have been carried out experimentally (Bi et al, 1995; Bi, 2007; Davidson, 1968; Fan et al, 1981; 1983; Kage et al, 1993; Musmarra et al, 1992; 1995; Roy et al, 1990; Sasic et al, 2005; 2006; Sun et al, 1994; Tallon and

\footnotetext{
* Corresponding author. email: kzhang@ncepu.edu.cn Received August 12, 2010
}

Davies, 1999; Tamarin, 1964; van der Schaaf et al, 1998; 1999; Zhao and Yang, 2003). Recently, Wang et al (2009b) experimentally investigated the pressure fluctuations, pressure wave velocity and pressure fluctuation major frequency in the gas-solid fluidized bed by using the standard deviation and auto- and cross-correlation functions. These investigations shows that pressure fluctuations are contributed from many sources, including local bubble-induced fluctuation, global bed oscillation and propagating pressure wave originating at different locations. It is clear that a detailed understanding of the interaction among bubble motion, bed oscillation and propagating pressure wave in the fluidized bed may hold the key in unlocking the phenomenon of complicated flow pattern formation. However, only a few sources concerning the cause of pressure fluctuations are discussed based on the experimental data due to the limitation of available measurement techniques.

As an alternative method, CFD simulations can provide more information about the pressure fluctuations in the fluidized beds. Generally, CFD models for gas-solid 
fluidization can be divided into Eulerian-Lagrangian and Eulerian-Eulerian models. The former is still currently difficult to use in an engineering installation. van Wachem et al (2001) suggested that the Eulerian-Eulerian method was a feasible approach for performing parametric investigations and scale-up and design studies in the fluidized beds. For the Eulerian-Eulerian model, however, there is still no consensus on solid-phase viscosity, solid stress modulus, and restitution coefficient (Zhang et al, 2005). It drives researchers (such as Chen et al, 1999; Foscolo and Gibilaro, 1987; Gibilaro, 2001) to develop different models for describing the hydrodynamics in the fluidized beds. Foscolo and Gibilaro (1987) proposed a one-dimensional Particle-Bed Model (PBM) to investigate fluid dynamic stability of fluidized suspensions. Later, Chen et al (1999) extended the formulation to two dimensions. The PBM identified the origin of the additional terms in the solid phase momentum balance equation as a result of fluidparticle interactions only, which violated Newton's third law. To overcome this shortcoming of the PBM, a simple mathematical model, introducing two additional force terms in both gas and particle phase momentum equations of Gidaspow's inviscid two-fluid model (Gidaspow, 1994), is suggested to describe hydrodynamics in the fluidized bed (Brandani and Zhang, 2006). Subsequently, a series of CFD simulations were conducted on the homogeneous, bubbling and collapsing behavior of Geldart A (1973) and B type particles (Zhang et al, 2008; Pei et al, 2009), jetting characteristics (Wang et al, 2007), and the scale-up method (Wang et al, 2009a). In this study, we will numerically investigate the origin and propagation of pressure fluctuations by using a pulsed gas method. The simulated pressure amplitude, pressure wave velocity, and pressure fluctuation frequency in the bubbling bed will be examined and compared with experimental measurements.

\section{Experimental}

\subsection{Experimental setup and operating conditions}

In this study, a rectangular fluidized bed made from transparent Plexiglass was used. It had a cross section of $0.025 \mathrm{~m} \times 0.300 \mathrm{~m}$ and a height of $2.000 \mathrm{~m}$ (Wang et al, 2009b). Resin particles with a diameter of $670 \mathrm{~mm}$ and a density of $1,474 \mathrm{~kg} / \mathrm{m}^{3}$, belonging to Geldart type B classification (Geldart, 1973), were used as the solid material. In a typical run, the resin was first loaded into the bed to a specified static bed height $\left(h_{0}=0.50 \mathrm{~m}\right)$. Then the gate valve was opened to introduce air into the bed, and the gas flow rate was controlled by the rotameter to maintain superficial gas velocities of 0.315 , $0.420,0.525$ and $0.630 \mathrm{~m} / \mathrm{s}$, respectively. The output signals of each pressure transducer were linearly proportional to pressure in the range of 0 to $10 \mathrm{kPa}$. A total 65,536 pressure measurements (denoted as $N$ ) were collected with a maximum sampling frequency of $1000 \mathrm{~Hz}$, and a filtered frequency of $500 \mathrm{~Hz}$. To calculate the power spectral density of the pressure signals, the 65,536 samples were divided into 64 segments (denoted as $L$ ).

\subsection{Data processing}

The real-time multi-channel data acquisition system provides various pressure signals in the gas-solid fluidized bed. Then, the standard deviations of pressure fluctuations, pressure wave velocity and major frequency are obtained when the pressure signals are processed by time-domain analysis or frequency-domain analysis.

The signal of interest, $p_{i}$, is a time series calculated or measured with $N$ data points at equidistant time intervals. Mean value of pressure signals is calculated by

$$
\bar{p}=\frac{1}{N} \sum_{i=1}^{N} p_{i}
$$

where $\bar{p}$ stands for mean pressure measured by pressure transducers, and $N$ is the total sampling number.

The standard deviation of pressure fluctuations, $\Delta p$, describing the amplitude of pressure fluctuations, is given below:

$$
\Delta p=\sqrt{\frac{1}{N-1} \sum_{i=1}^{N}\left(p_{i}-\bar{p}\right)^{2}}
$$

The cross-correlation function of pressure signals between two adjacent taps, $h_{\mathrm{j}}$ and $h_{\mathrm{k}}$, is expressed as

$$
\varphi_{j, k}(\tau)=\lim _{T_{s} \rightarrow \infty} \frac{1}{T_{s}} \int_{-T_{s} / 2}^{T_{s} / 2} p_{j}(t) p_{k}(t+\tau) \mathrm{d} t
$$

where $T_{s}$ is the sampling time, $p_{\mathrm{j}}(t)$ is the pressure value sampled at $h_{\mathrm{j}}$ when time is $\mathrm{t}$, and $p_{\mathrm{k}}(t+\tau)$ is the pressure value sampled at $h_{\mathrm{k}}$ when time is $(t+\tau)$ by considering time shift, $\tau$, between $h_{\mathrm{j}}$ and $h_{\mathrm{k}}$. The average time required for a fluctuation waveform to travel between these two locations is the transit time, $\tau_{\mathrm{p}}$, where the cross-correlation coefficient is the maximum (Fan et al, 1983). Accordingly, the pressure wave velocity, $u_{\mathrm{w}}$, can be calculated by

$$
u_{w}=\frac{L_{p}}{\tau_{p}}
$$

where, $L_{\mathrm{p}}$ is the known distance between the two detecting locations $\left(h_{\mathrm{j}}\right.$ and $\left.h_{\mathrm{k}}\right)$.

The auto-correlation function of pressure signals at $h_{\mathrm{j}}$ is given below:

$$
\phi_{j, j}(\tau)=\lim _{T_{s} \rightarrow \infty} \frac{1}{T_{s}} \int_{-T_{s} / 2}^{T_{s} / 2} p_{j}(t) p_{j}(t+\tau) d t
$$

Power spectral density is one important frequency-domain analysis method. The variance of an estimation in the power spectrum is the order of the square of the power spectral density, and will not decrease with increasing number of samples. This is the case, because a single power spectrum can be seen as one sample in the frequency domain. In order to decrease the variance, the power spectrum is estimated as an average of a number of sub-spectra, the number chosen to get a satisfactory trade between frequency resolution and variance. Hence, the time series is divided into $L$ segments of individual length $N_{\mathrm{s}}$ which are represented as

$$
x_{i}(n)=x_{i}\left(n+i N_{s}\right) \quad n=1,2, \cdots, N_{\mathrm{s}} ; \quad i=1,2, \cdots, L
$$

The power-spectrum estimate of each segment is 


$$
p_{x x}^{\prime}(f)=\frac{1}{N_{s} W}\left|\sum_{n=1}^{N_{s}} x_{i}(n) w(n) \exp (-j 2 \pi f n)\right|^{2}
$$

where, $W$ is normalized by a factor of the power in the window function, $w(n)$. Thus,

$$
W=\frac{1}{N_{s}} \sum_{n=1}^{N_{s}} w^{2}(n)
$$

The average power spectrum becomes

$$
p_{x x}(f)=\frac{1}{L} \sum_{i}^{L} p_{x x}^{\prime}(f)
$$

Equations (6)-(9) comprise the Welch method of power spectrum estimation without overlap between data segments. A Hamming window is used as the window function, $w(n)$ is given by

$$
w(n)= \begin{cases}\frac{1}{T_{s}}\left(0.54+0.46 \cos \left(\frac{\pi t}{T_{s}}\right)\right) & 0 \leq|t| \leq T_{s} \\ 0 & |t| \geq T_{s}\end{cases}
$$

\section{CFD simulation}

\subsection{A simple model}

This model adopts the principles of conservation of mass and momentum. A detailed derivation of this model can be found in the literature (Brandani and Zhang, 2006). The equations for conservation of mass and momentum for two phases are given below.

Continuity equation $(i=\mathrm{g}, \mathrm{p})$ :

$$
\frac{\partial \varepsilon_{i}}{\partial \boldsymbol{t}}+\nabla \cdot\left(\varepsilon \boldsymbol{u}_{i}\right)=0
$$

Momentum equation ( $i=\mathrm{g}, \mathrm{p}$, and $j=\mathrm{p}, \mathrm{g})$ :

$$
\frac{\partial\left(\varepsilon_{g} \rho_{i} \boldsymbol{u}_{i}\right)}{\partial \boldsymbol{t}}+\nabla \cdot\left(\varepsilon_{i} \rho_{i} \boldsymbol{u}_{i} \boldsymbol{u}_{i}\right)=-\beta\left(\boldsymbol{u}_{i}-\boldsymbol{u}_{j}\right)-\varepsilon_{i} \nabla \boldsymbol{p}+\varepsilon_{i} \rho_{i} \boldsymbol{g}-\boldsymbol{F}_{a d, i}
$$

According to the closure principles governing the equations, interphase drag coefficient, $\beta$, and additional forces, $\boldsymbol{F}_{a d, i}$, need to be obtained from the basic fluid-field variables. In the two-dimensional bed,

$$
\begin{aligned}
& \boldsymbol{F}_{a d, g}=\mathrm{d}_{p}\left[\left(1-2 \varepsilon_{g}\right) \rho_{p}+2 \varepsilon_{g} \rho_{g}\right] \boldsymbol{g} \cdot \nabla \varepsilon_{g} \boldsymbol{i} \\
& \boldsymbol{F}_{a d, p}=\mathrm{d}_{p}\left[2 \varepsilon_{p} \rho_{p}+\left(1-2 \varepsilon_{p}\right) \rho_{g}\right] \boldsymbol{g} \cdot \nabla \varepsilon_{p} \boldsymbol{i}
\end{aligned}
$$

where, $\boldsymbol{i}$ is the unit vector, which is in the same direction as that of acceleration due to gravity, $g$.

The interphase drag coefficient, $\beta$, is a function of the particle drag coefficient, $C_{D}$

$$
\beta=\mathrm{C}_{D} \frac{3 \varepsilon_{p} \rho_{g}\left|\left(\boldsymbol{u}_{p}-\boldsymbol{u}_{g}\right)\right|}{4 \mathrm{~d}_{p}} \varepsilon_{g}^{-1.8}
$$

and the particle drag coefficient $C_{D}$ can be obtained from the empirical Dallavalle relation (Gibilaro, 2001).

$$
C_{D}=\left(0.63+\frac{4.8}{\sqrt{\operatorname{Re}}}\right)^{2}
$$

where

$$
\operatorname{Re}=\frac{\rho_{g} \varepsilon_{g}\left|\boldsymbol{u}_{g}-\boldsymbol{u}_{p}\right| \mathrm{d}_{p}}{\mu_{g}}
$$

\subsection{Simulation procedure}

Numerical calculations were conducted using the commercial CFD package, CFX4.4. The gravity and buoyancy in the momentum equations could be defined directly in the Command file, while the interphase drag and additional forces in Brandani and Zhang model (Zhang et al, 2005; Brandani and Zhang, 2006) were obtained by calling user-defined Fortran subroutines. Resin used in the experiments was used as solid phase. Initially, the bed was operated at the incipient fluidization state $\left(u_{\mathrm{mf}}=0.21 \mathrm{~m} / \mathrm{s}\right.$ and $\varepsilon_{\mathrm{mf}}=0.409$ ), and the static bed height was $0.50 \mathrm{~m}$. During the simulation, a grid system, 200 (vertical) $\times 30$ (horizontal), was used. Time step and maximum solid volume fraction were selected as $1.0 \times 10^{-4}$ seconds and 0.6 , respectively.

The boundary condition at the top of the bed was the pressure boundary, i.e., ambient atmosphere. The effects of the front and back walls were ignored as the simulations were carried out in the two-dimensional formation. Left and right boundaries were treated as impermeable and rigid walls, where the no-slip velocity boundary conditions were employed for both gas and solid phases. A solid volume fraction of $10^{-10}$ was set in the freeboard, which could provide more realistic results for particle velocity and good convergence.

Under gas pulse conditions, the pulse gas was injected into the fluidized bed with $0.30 \mathrm{~m}$ (width) $\times 2.00 \mathrm{~m}$ (height) through a central nozzle $\left(d_{0}=0.02 \mathrm{~m}\right)$ in the bottom. Gas velocity and pulse time were $1.05 \mathrm{~m} / \mathrm{s}$ and $0.05 \mathrm{~s}$, respectively.

Under freely bubbling conditions, numerical simulations were conducted in a two-dimensional fluidized bed with a width of $0.30 \mathrm{~m}$ and a height of $2.00 \mathrm{~m}$. The bottom of the bed was modeled as a uniform velocity inlet condition and the gas velocity was maintained at $0.315 \mathrm{~m} / \mathrm{s}, 0.420 \mathrm{~m} / \mathrm{s}, 0.525$ $\mathrm{m} / \mathrm{s}$, and $0.630 \mathrm{~m} / \mathrm{s}$, respectively.

\section{Results and discussion}

\subsection{Origin of pressure fluctuations}

Fig. 1 shows a typical response of the fluidized bed to a gas pulse. All particles in the bed are accelerated by the drag force between the gas and solid phases when a gas pulse is applied. The acceleration leads to the difference in the gas and particle velocity. As a result, the bed voidage decreases homogeneously throughout the bed. At a position, therefore, the pressure reaches a maximum value corresponding to a maximum drag force. Then the particles are decelerated by gravity, and the pressure reaches a minimum value and then increases again. From Fig. 1 and Fig. 2, it can be seen that the bubble generates above the nozzle and starts 
to disturb the movement of gas and solids in the bed. The pressure above the bubble gradually increases because the bed surface is elevated due to the presence of a rising gas bubble when the bubble detaches from the nozzle and moves upwards. However, the pressure begins to decrease due to the increasing voidage when the bubble passes through. Moreover, behind the bubble, the voidage is apparently higher than the minimum fluidization voidage, and an expanded state appears with a higher voidage, resulting in a lower pressure. The expanded state is unstable and easily collapses by small disturbance. When the bubble is close to the interface between the dense phase and the freeboard, it disturbs the expanded state of the bed. Therefore, the pressure near the bed surface gradually decreases to a lower value, and then sharply increases when the bubble reaches and goes through the interface. The pressure in the lower bed mainly reflects the change in the voidage. When the bubble at the bed surface is exploded, the consequent change of voidage cannot instantly propagate down in the bed. The response of voidage in the bed strongly resembles that of the disturbance generated by a step compression of a fluidized bed with a permeable piston, as described by Musmarra et al (1995).

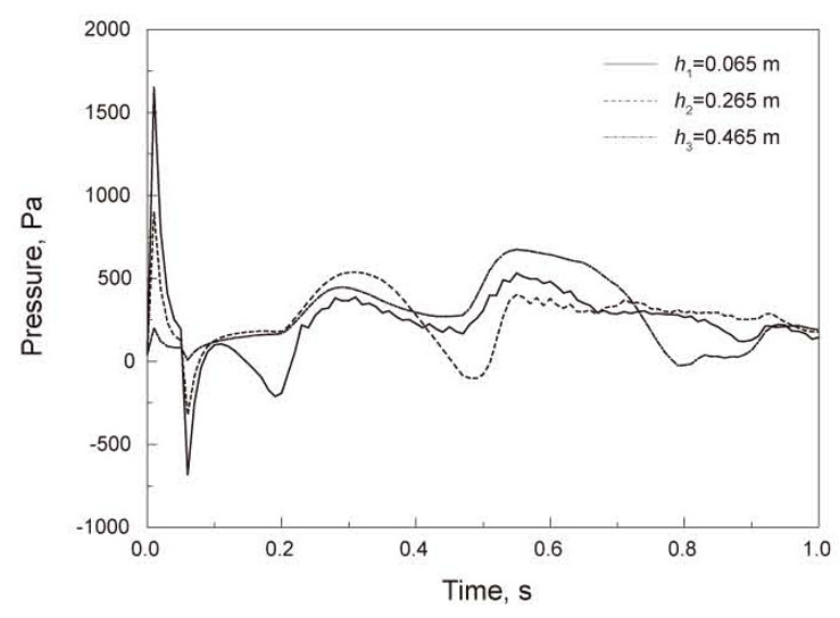

Fig. 1 Typical response of the fluidized bed to a gas pulse at three vertical positions (pulse gas velocity of $1.05 \mathrm{~m} / \mathrm{s}$ and pulse time of $0.05 \mathrm{~s}$ )

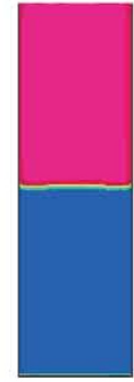

$\mathrm{t}=0.00 \mathrm{~s}$

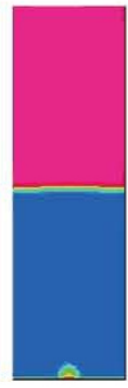

$0.05 \mathrm{~s}$

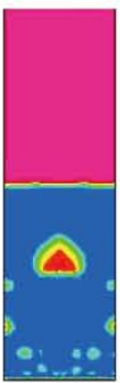

$\mathrm{t}=0.55 \mathrm{~s}$

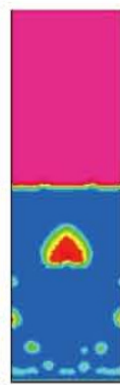

$0.60 \mathrm{~s}$

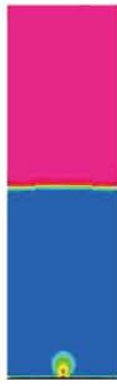

$0.10 \mathrm{~s}$

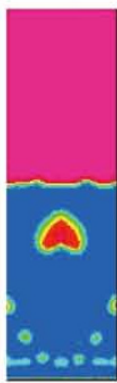

$0.65 \mathrm{~s}$

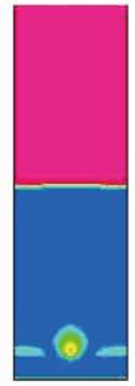

$0.15 \mathrm{~s}$

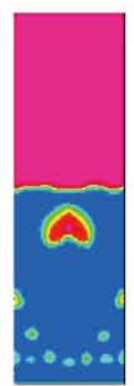

$0.70 \mathrm{~s}$

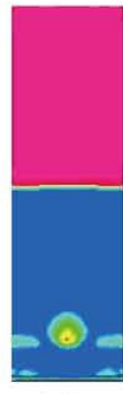

$0.20 \mathrm{~s}$

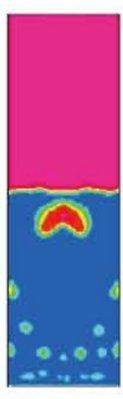

$0.75 \mathrm{~s}$

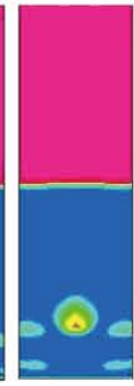

$0.25 \mathrm{~s}$

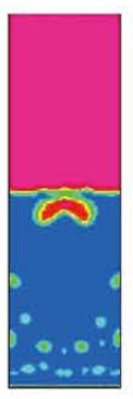

$0.80 \mathrm{~s}$

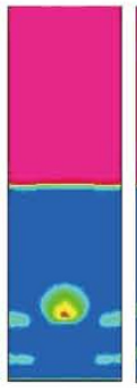

$0.30 \mathrm{~s}$

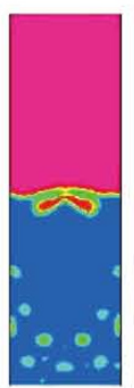

$0.85 \mathrm{~s}$

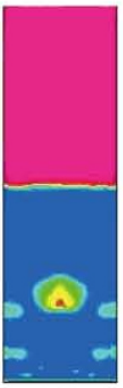

$0.35 \mathrm{~s}$

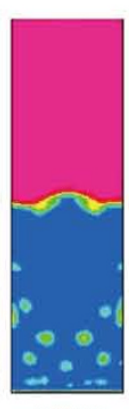

$0.90 \mathrm{~s}$

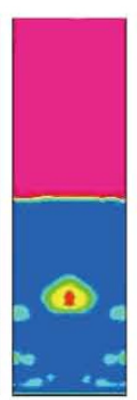

$0.40 \mathrm{~s}$

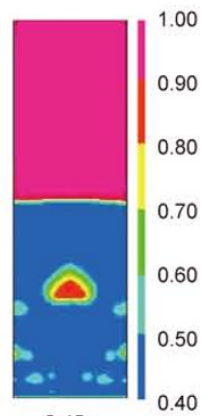

$0.45 \mathrm{~s}$

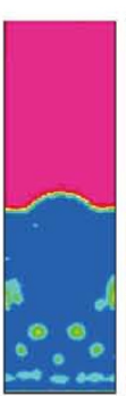

$0.95 \mathrm{~s}$

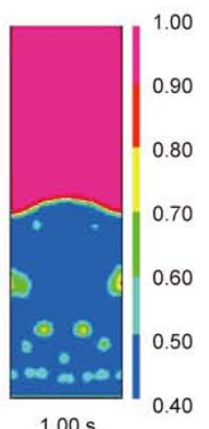

$1.00 \mathrm{~s}$

Fig. 2 Snapshots of solid volume fraction distributions for a gas pulse (pulse gas velocity of $1.05 \mathrm{~m} / \mathrm{s}$ and pulse time of $0.05 \mathrm{~s}$ )

\subsection{Propagation of pressure waves}

Musmarra et al (1992) investigated the propagation of a single disturbance and continuous injection of a single bubble or jet from a vertical tube above an undisturbed section of the fluidized bed. Bi et al (1995) also used a similar method to investigate the propagation of a pressure wave in a fluidized bed of FCC particles. When a gas pulse is applied to the fluidized bed, the pressure waves are propagated through the gas-solid mixture medium. As shown in Fig. 3, the peaks of the pressure pulse generated by the injection of a gas pulse are shifted upwards with an increase in the vertical height.
Moreover, the time shift can be observed between the peaks of two different vertical heights. This indicates that the pressure wave is propagated in fluidized beds at a certain speed.

\subsection{Intensity of pressure fluctuations}

At a low operating gas velocity $\left(u_{0}=0.420 \mathrm{~m} / \mathrm{s}\right)$, the amplitude of pressure fluctuations is very small since the effect of gas turbulence on solid particles is not significant (see Fig. 4). The amplitude of pressure fluctuations increases greatly with the increase of the operating gas velocity as the 
particles are stirred strongly by the fluidizing gas. Moreover, when both the static bed height and the operating gas velocity are fixed, the standard deviation of pressure fluctuations varies with increasing vertical height of the bed over the distributor because of the change of bubble size as these bubbles move upward. When the vertical distance is greater than $0.3 \mathrm{~m}$ above the distributor, however, the standard deviation of pressure fluctuations sharply decreases because the bubble size is larger than the maximum stable bubble size and these bubbles are broken up into small bubbles.

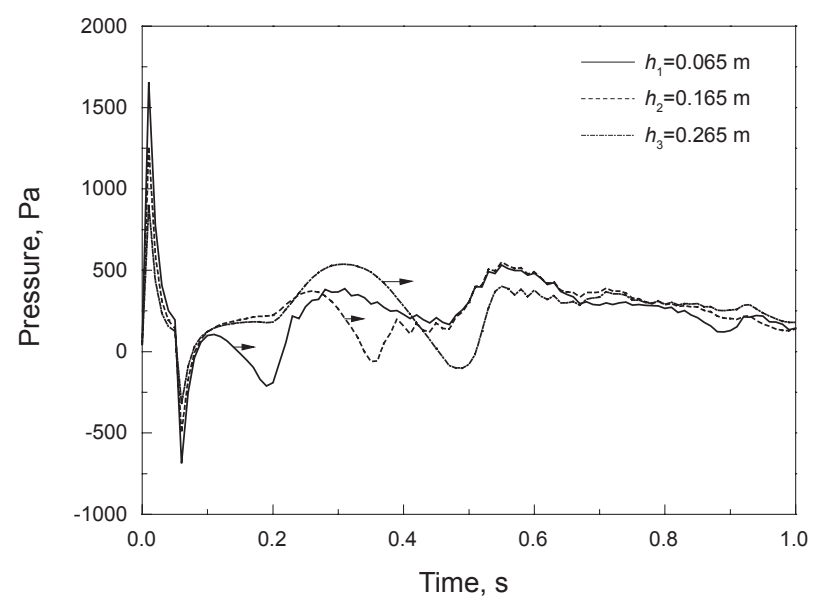

Fig. 3 Propagation of a gas pulse at different vertical positions (pulse gas velocity of $1.05 \mathrm{~m} / \mathrm{s}$ and pulse time of $0.05 \mathrm{~s}$ )

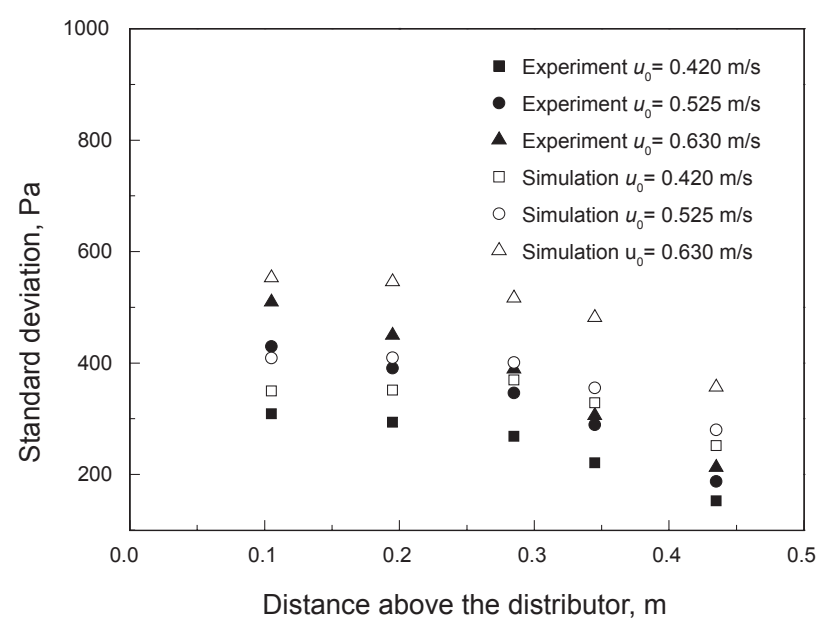

Fig. 4 Pressure standard deviation vs. vertical position in the freely bubbling bed

\subsection{Pressure wave velocity}

Some researchers have measured the pressure wave propagation velocity in gas-solid packed and fluidized beds (Bi et al, 1995; Musmarra et al, 1992; Roy et al, 1990; Tallon and Davies, 1999). For example, Roy et al (1990) found that the velocity of the pressure wave was quite low, of the order of $10 \mathrm{~m} / \mathrm{s}$ for gas at ambient pressure, independent of the gas and the temperature, but proportional to the square root of the pressure. Bi et al (1995) also observed that pressure waves were propagated in fluidized beds at a speed of the order of $10 \mathrm{~m} / \mathrm{s}$, and the velocity tended to be higher when the bed was defluidized. Tallon and Davies (1999) showed that the pressure wave speed increased with increasing wave frequency and reached a maximum value at a certain frequency before decreased with further increasing wave frequency. Fig. 5 shows the cross-correlation functions between the pressure fluctuation signals measured in two adjacent vertical positions. Obviously, the pressure fluctuation signals have a slight time shift between the upper and lower vertical positions in the fluidized bed. Then, the average propagation velocity of the pressure wave, $u_{\mathrm{w}}$, can be obtained from Equation (4) above.

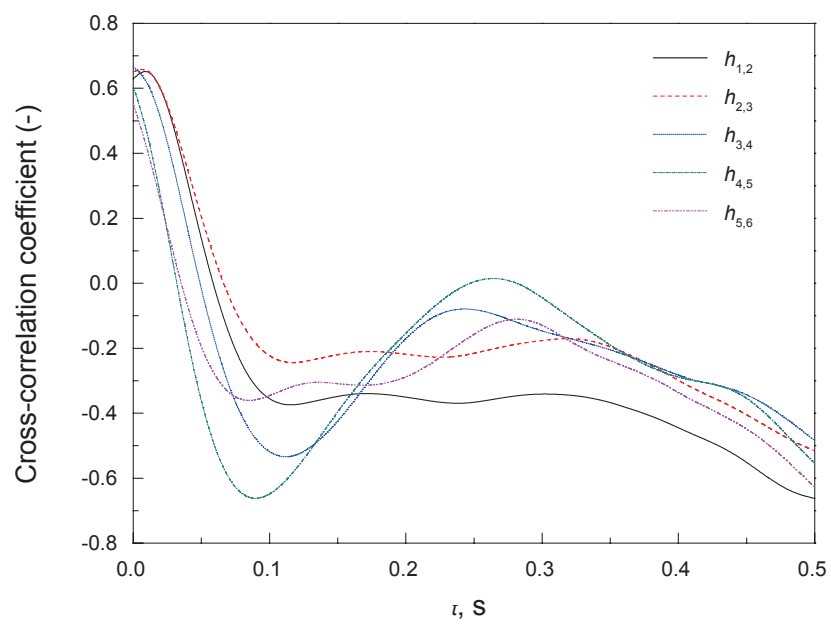

Fig. 5 Cross-correlation coefficients of pressure fluctuations between two adjacent vertical positions on the bed axis in the freely bubbling bed (Simulation: $u_{0}=0.420 \mathrm{~m} / \mathrm{s}$ )

As shown in Fig. 6, the effect of operating gas velocity on the pressure wave velocity can be ignored at the same static bed height. Moreover, the model prediction results agree well with the experimental values, which are about $6 \mathrm{~m} / \mathrm{s}$. For the freely bubbling state, Bi (2007) reported the similar results, though the wave velocity was around $5 \mathrm{~m} / \mathrm{s}$.

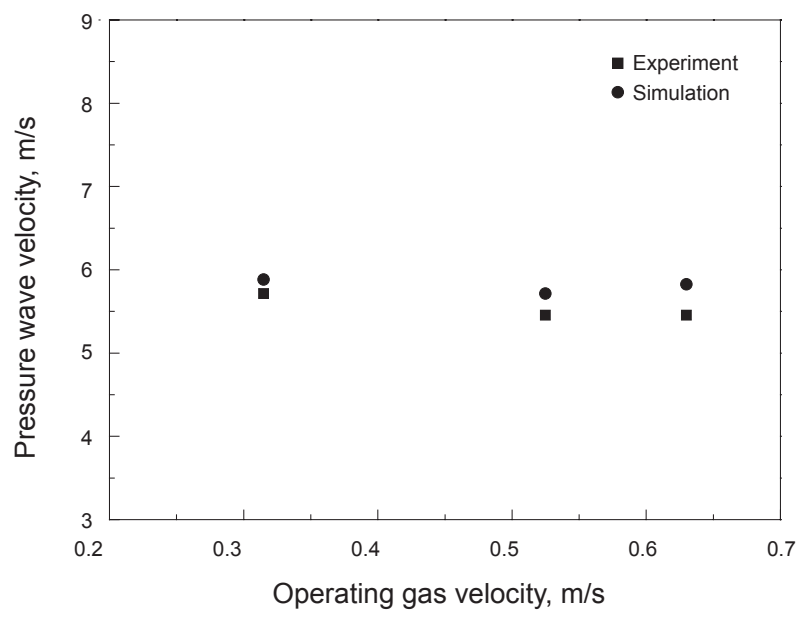

Fig. 6 Effect of operating gas velocity on pressure wave velocity in the freely bubbling bed 


\subsection{Pressure fluctuation frequency}

The pressure fluctuation signals in the gas-solid fluidized bed appear obviously periodic at six vertical heights as seen in Fig. 7, which is in agreement with the result reported by Lirag and Littman (1971). The ratio of random to periodic components in the pressure fluctuation signals decreases with increasing operating gas velocity, and the results at $\mathrm{h}_{4}$ position are shown in Fig. 8 as an example.

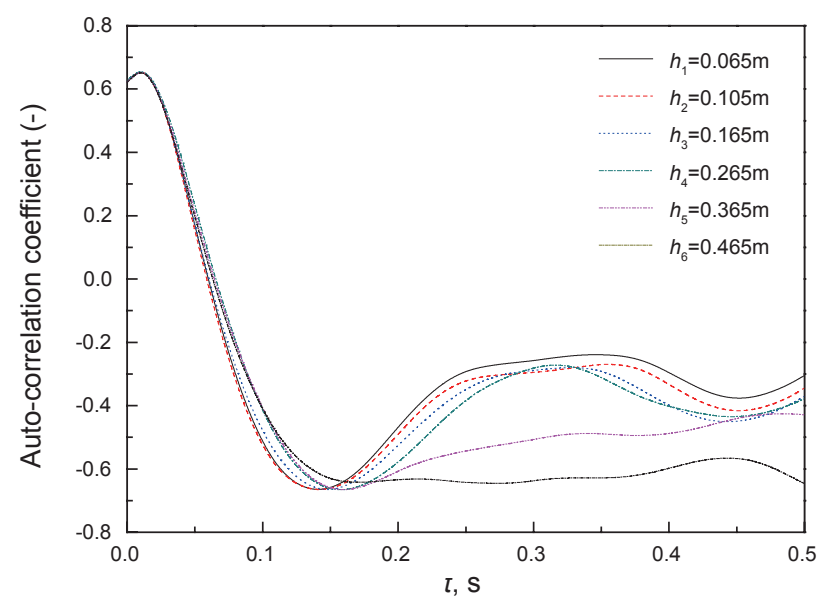

Fig. 7 Auto-correlation coefficients along the bed height in the freely bubbling bed (Simulation: $u_{0}=0.630 \mathrm{~m} / \mathrm{s}$ )

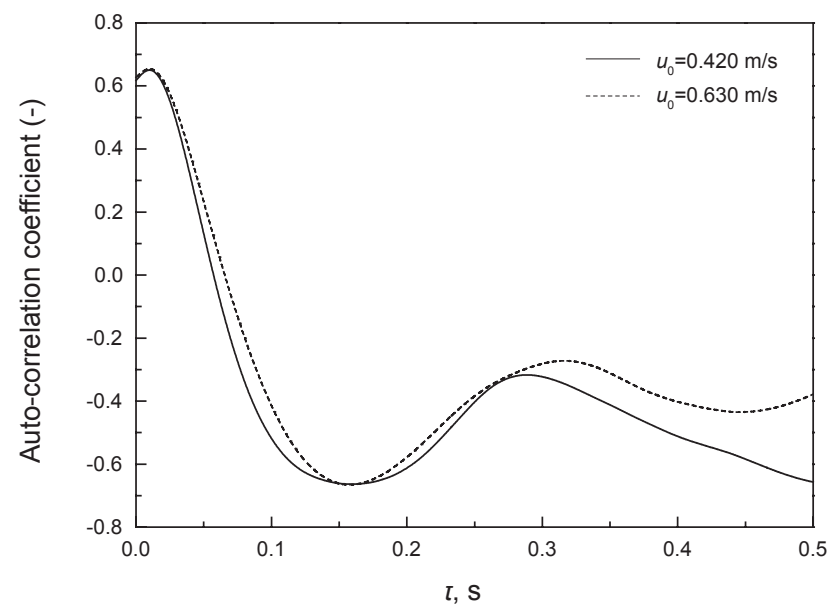

Fig. 8 Auto-correlation coefficients at $\mathrm{h}_{4}$ position (Simulation)

From Fig. 9, two peak frequencies are observed in the power spectrum of the pressure fluctuations when the fluidizing gas is uniformly distributed in the gas inlet. Similar results obtained by Kage et al (1993) were three peak frequencies for the pressure fluctuations measured in the plenum chamber. One, independent of the variation of the operating gas velocity, was found to be in agreement with the natural frequency as predicted by the plenum chamber compression theory (Lirag and Littman, 1971). The second peak frequency was found to be associated with the bubble eruption at the upper bed surface as measured with a video camera. The third one increased with increasing gas flow rate, and was related to bubble formation on the gas distributor.
Following the explanation by Kage et al (1993), the two peak frequencies in Fig. 9 are associated with bubble formation above the distributor and the bubble eruption at the upper bed surface, respectively.
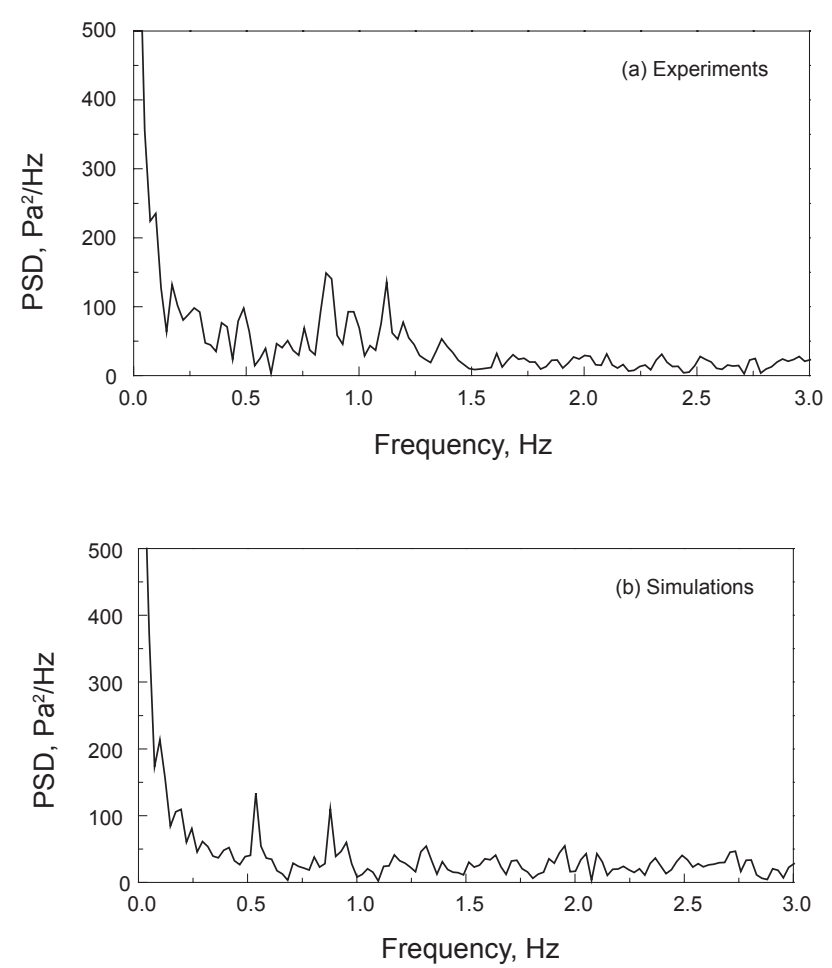

Fig. 9 Power spectrum density of pressure fluctuations at $h_{4}$ position $\left(u_{0}=0.630 \mathrm{~m} / \mathrm{s}\right)$

The effect of the operating gas velocity on the pressure fluctuation major frequency is shown in Fig. 10. It is clear that the major frequency of pressure fluctuations at the same vertical position slightly increases with increasing operating gas velocity. Moreover, the same variation trends of major frequency with increasing gas velocity are also predicted by experimental and simulated methods.

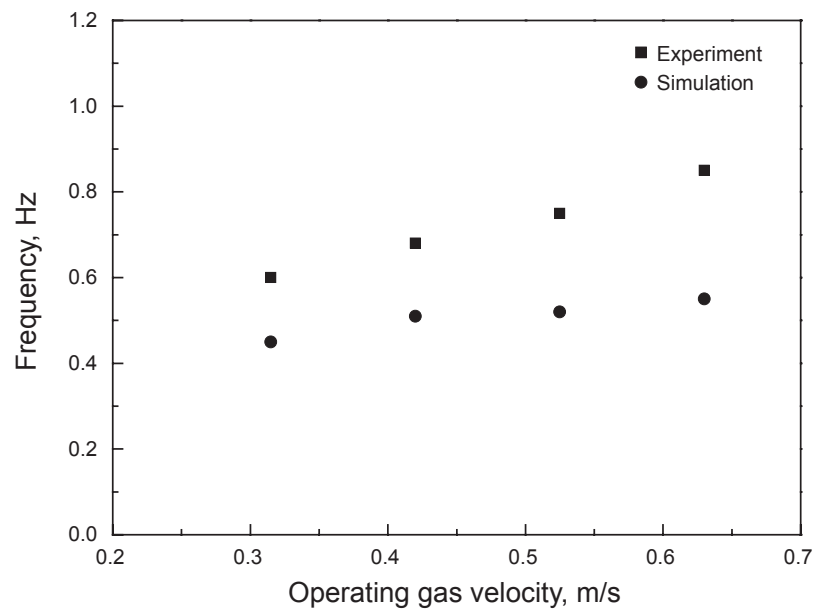

Fig. 10 Effect of operating gas velocity on pressure fluctuation frequency at $\mathrm{h}_{4}$ position 


\section{Conclusions}

By comparing with experimental data, a simple hydrodynamic model based on two-fluid theory is used to investigate numerically the pressure fluctuation characteristics in gas-solid fluidized beds. The main conclusions are as follows:

(a) The pressure fluctuations originate above the distributor when a pulse of gas is injected into the fluidized bed. The pressure above the bubble gradually increases, and then decreases while the bubble pass through the position detected. After the bubble passage through the bed surface, the pressure near the bed surface gradually decreases to a lower value.

(b) In freely bubbling beds, the amplitude of pressure fluctuations, which is related to the vertical height, increases with an increase in the operating gas velocity. When bubble sizes are larger than the maximum stable bubble size, the amplitude of pressure fluctuations decreases. The pressure wave propagation velocity is independent of the operating gas velocity and is about $6 \mathrm{~m} / \mathrm{s}$ in the range of this study.

(c) The pressure signals in the bed have obviously periodic characteristics. When the fluidizing gas is uniformly distributed in the gas inlet, only two peak frequencies are observed in the power spectrum of the pressure fluctuations. These are associated with bubble formation above the distributor and bubble eruption at the upper bed surface, respectively. Moreover, the major frequency of pressure fluctuations at the same vertical position is affected slightly by the operating gas velocity.

\section{Nomenclatures}

$C_{D} \quad$ Particle drag force coefficient

$d_{0} \quad$ Nozzle slit, $\mathrm{m}$

$d_{\mathrm{p}} \quad$ Particle diameter, $\mathrm{m}$

$f \quad$ Frequency, $\mathrm{Hz}$

$\boldsymbol{F}_{\text {ad }} \quad$ Additional force, $\mathrm{N} / \mathrm{m}^{3}$

g

$h_{0}$

$h$

$h_{i}$

$\boldsymbol{i}$

$L$

$N$

$N_{\mathrm{s}}$

$L_{\mathrm{p}}$

p

$p_{\text {i }}$

$P x x$

$P^{\prime} x x$

$\bar{p}$

$\triangle P$

Re

$t$

$T_{\mathrm{s}}$

$\boldsymbol{u}$

$u_{0}$

$\begin{array}{ll}u_{\mathrm{mf}} & \text { Minimum fluidization velocity, } \mathrm{m} / \mathrm{s} \\ u_{\mathrm{w}} & \text { Pressure wave velocity, } \mathrm{m} / \mathrm{s} \\ w & \text { Window function } \\ x_{i} & \text { Time series of pressure signal, Pa } \\ \text { Greek letters } \\ \beta & \text { Interphase drag coefficient } \\ \varepsilon & \text { Volume fraction } \\ \varepsilon_{\mathrm{mf}} & \text { Minimum fluidization voidage } \\ \phi_{j, j} & \text { Auto-correlation at } j \text { pressure tap } \\ \phi_{j, k} & \text { Cross-function between } j \text { and } k \text { pressure taps } \\ \phi_{p} & \text { Sphericity of particles } \\ \mu & \text { Viscosity, Pa·s } \\ \rho & \text { Density, } \mathrm{kg} / \mathrm{m}^{3} \\ \tau & \text { Shift time, } \mathrm{s} \\ \tau_{\mathrm{p}} & \text { Maximum time delay of pressure signals at different } \\ & \quad \text { measurement taps, } \mathrm{s} \\ \text { Subscripts } \\ g & \text { Gas } \\ p & \text { Solid }\end{array}$

\section{Acknowledgements}

Financial support from National Basic Research Program of China (No. 2009CB219801), National Natural Science Foundation of China (No. 20976191), International Cooperative Program of Guizhou Province([2009]700110), and Program for New Century Excellent Talents in University (NCET-09-0342) is gratefully acknowledged.

\section{References}

Bi H T, Grace J R and Zhu J. Propagation of pressure wave and forced oscillations in gas-solid fluidized beds and their influence on diagnostics of local hydrodynamics. Powder Technol. 1995. 82(3): 239-53

Bi H T. A critical review of the complex pressure fluctuation phenomenon in gas-solids fluidized beds. Chem. Eng. Sci. 2007. 62(13): 3473-3493

Brandani S and Zhang K. A new model for prediction of the behaviour of fluidized bed. Powder Technol. 2006. 163(1-2): 80-87

Chen Z, Gibilaro L G and Foscolo P U. Two-dimensional voidage waves in fluidized beds. Ind. Eng. Chem. Res. 1999. 38(3): 610-620.

Davidson J F. Introduction by rapporteur. Inst. Chem. Engineers Symp. Series. 1968. 30: 3-11

Fan L T, Ho T C, Hiraoka S, et al. Pressure fluctuations in a fluidized bed. AIChE J. 1981. 27(3): 388-396

Fan L T, Ho T C, and Walawender W P. Measurements of the rise velocities of bubble, slug and pressure waves in a gas-solid fluidized bed using pressure fluctuation signals. AIChE J. 1983. 29(1): 33-39

Foscolo P U and Gibilaro L G. Fluid dynamic stability of fluidized suspension: the particle bed model. Chem. Eng. Sci. 1987. 42(6): 1489-1500

Geldart D. Types of gas fluidization. Powder Technol. 1973. 7(5): 285292

Gibilaro L G. Fluidization Dynamics. London: Butterworth Heinemann. 2001

Gidaspow D. Multiphase Flow and Fluidization. Boston: Academic Press. 1994

Kage H, Iwasaki N and Matsuno Y. Frequency analysis of pressure fluctuation in plenum as a diagnostic method for fluidized beds. AIChE. Symp. Series. 1993. 89(296): 184-190

Kim S W, Namkung W and Kim S D. Solid behavior in freeboard of 
FCC regenerator. J. Chem. Eng. Japan. 2000. 33(1): 78-85

Lirag R C and Littman H. Statistical study of the pressure fluctuations in a fluidized bed. AIChE Symp. Ser. 1971. 67(116): 11-22

Musmarra D, Vaccaro S, Filla M, et al. Propagation characteristics of pressure disturbances originated by gas jets in fluidized beds. Int. J. Multiphase Flow. 1992. 18(6): 965-976

Musmarra M, Poletto S, Vaccaro R, et al. Dynamic wave in fluidized beds. Powder Technol. 1995. 82(3): 255-268

Pei P, Zhang K, Lu E W, et al. CFD simulation of bubbling and collapsing characteristics in a gas-solid fluidized bed. Petrol. Sci. 2009. 6(1): 69-75

Roy R, Davidson J F and Tupogonov V G. The velocity of sound in fluidised beds. Chem. Eng. Sci. 1990. 45(11): 3233-3245

Sasic S, Leckne B and Johnsson F. Fluctuations and waves in fluidized bed systems: the influence of the air-supply system. Powder Technol. 2005. 153(3): 176-195

Sasic S, Leckner B and Johnsson F. Time-frequency investigation of different modes of bubble flow in a gas-solid fluidized bed. Chem. Eng. J. 2006. 121(1): 27-35

Sun J G., Chen M M and Chao B T. Modeling of solids global fluctuations in bubbling fluidized beds by standing surface waves. Int. J. Multiphase Flow. 1994. 20(2): 315-338

Tallon S and Davies C E. Propagation of gas phase pressure fluctuations in particulate beds. AIChE Symp. Series. 1999. 95: 298-303

Tamarin A I. The origin of self-excited oscillations in fluidized bed. Int. Chem. Eng. 1964. 4(1): 50-54

van der Schaaf J, Schouten J C and van den Bleek C M. Origin propagation and attenuation of pressure waves in gas-solid fluidized beds. Powder Technol. 1998. 95(3): 220-233

van der Schaaf J, Schouten I C, Johnsson F, et al. Multiple modes of bed mass oscillation in gas-solid fluidized bed. In: Proceedings of the 15th International Conference on Fluidized bed Combustion, Savannah, Georgia, 1999

van Wachem B G M, Schouten J C, van den Bleek C M, et al. Comparative analysis of CFD models of dense gas-solid systems. AIChE J. 2001. 47(5): 1035-1051

Wang Q C, Zhang K, Brandani S, et al. Scale-up strategy for the jetting fluidized bed using a CFD model based on two-fluid theory. Can. J. Chem. Eng. 2009a. 87(2): 204-210

Wang Q C, Zhang K, Ren J T, et al. Pressure fluctuations in a gas-solid fluidized bed of Geldart B classification particles. Journal of Fuel Chemistry and Technology (China). 2009b. 37(6): 763-768

Wang Q C, Zhang K, Sun G G, et al. CFD simulation of fluid dynamics in a gas-solid jetting fluidized bed. Int. J. Chem. React. Eng. 2007. 5: A112

Zhang K, Brandani S and Bi J C. Computational fluid dynamics for dense gas-solid fluidized beds. Prog. Nat. Sci. 2005. 15(Special Issue): $42-51$

Zhang K, Brandani S, Bi J C, et al. CFD simulation of fluidization quality in the three-dimensional fluidized bed. Prog. Nat. Sci. 2008. 18(6): 729-733

Zhao G B and Yang Y R. Multiscale resolution of fluidized-bed pressure fluctuations. AIChE J. 2003. 49(4): 869-882

(Edited by Zhu Xiuqin) 